\title{
On the Regulation of Advertising Law on the Bid Ranking
}

\section{of Search Engine}

\author{
Jinlong Zhao \\ College of Political Science and Law, Hebei University \\ 180 Wusi East Road, Baoding, Hebei Province, China \\ E-mail: jinlong_zhao@hotmail.com \\ Yu Wang \\ College of Political Science and Law, Hebei University \\ 180 Wusi East Road, Baoding, Hebei Province, China
}

\begin{abstract}
In the virtual network world in information age, the legal authority is being faced with constant challenges. While operation model of bid ranking of search engine not only creates enormous economic benefit, but also makes the authenticity and fairness of information searching be increasingly questioned, which requires to be regulated by law objectively. According to the China's existing laws, the application of law is still blank in this regard. Whether the bid ranking of search engine should be regulated and how the legal relationships should be regulated by Advertising Law still remain open. Taking the Baidu search engine for an example, the authors will explore relevant legal regulations and put forward some proposal to to regulate the bid ranking under the perspective of Advertising Law.
\end{abstract}

Keywords: Search Engine, Bid Ranking, Advertising Law, Regulation

With the growing up and development of Internet media, more and more problems related to internet have emerged. The infringement reports of bid ranking and false advertising promotion by Baidu illustrated some gaps in legal regulation. From the perspective of the regulations of Advertising Law, the authors try to analyse the relevant questions with hope to improve the legislation, judicial administration and legal enforcement.

\section{The Commercial Purpose and Negative Effect of Bid Ranking of Search Engine}

\subsection{The Commercial Purpose of Bid Ranking of Search Engine}

Bid ranking refers to a pay-for-performance network promotion introduced by the search companies. Its specific approach is based upon a principle as following: after buying this kind of service, the advertiser will register a certain number of keywords, then the website of those advertisers who buy the same keywords will be ranked by the fee paid to the search engine, the bidder who pay the highest to buy the same keywords could be ranked top so that its web page could be seen by consumer earliest. It is the search engines that order this rank, which will be illustrated in the searching outcome of consumer.

Bid ranking plays a key role in the course of Baidu's service for the enterprises and consumers. First, as to the enterprises, they could advertise their products and services by making use of search engine, namely, they bid for the ranking and make their information showed to the consumers first. Through this man-made way, the justice and fairness order of the search engine is undermined by people, however, on which there is no express provision in China Advertising Law. Just like what the manager of Baidu company said in 2003, Bid Ranking already became the best tool for their promotion and marketing. It is true that more and more medium and small enterprises have benefited from Baidu' bid ranking model and have relied on it gradually. Much domestic enterprises use search engine to seize the market and create a brilliant performance, for example, the click-through rate of Taobao website exceeds Yiqu website within one year through purchase the bid ranking service in Baidu.(Ma Xiaolong,2003,38) Another example is Medicine for All website, after buying the service offered by Baidu, the click-through rate of its website---Medicine for All had ranked top one for a long time.In this circumstance, the possibility of being searched of other enterprises who did not purchase the bid ranking service in the same industry will be reduced greatly. It is held that fairness and efficiency were measured by money and the justice value of search engines is belittled by the interests. Second, as for Baidu Company, bid ranking mode could bring about economic benefit, which is the original dynamica of this operation model. According to the third quarter financial disclosure of 2008, the operation income of Baidu Company is approximate 919.1 million yuan, up $85.1 \%$ compared with the same quarter of last year. Among that, the network 
marketing income is approximate 918.2 million yuan, most of which came from bid ranking. Furthermore, to the consumers, when clicking on Baidu search engine to find a merchant by the keyword, they can quickly browse the website link of the business, but it is possible that they could not find their demandable information in the first few pages on website because of the impact of bid ranking.

Among the three civil parties of Baidu Company, the enterprise and the consumer exists two legal relationships separately, and from which we can identify the legal status of Baidu Company. Baidu company entered into a synallagmatic contract with one enterprise, which is the first legal relationship; all the relevant information Baidu company provides to consumers is based on consumers' clicking, which is the second legal relationship. The two contracts are independent, namely, being equal, fair and having no bad influence on each other.

\subsection{The Negative Effect of Bid Ranking of Search Engine}

In practice, bid ranking mode of search engine will produce some bad effects as followings:

First, the ranking is based on the business services by purchasing keywords so as to give buyer' website link preference, which ignores those links which contained the keywords' real meaning. We can survey the situation by put into different keywords in Baidu' search bar.

Second, the search engine companies that take the bid ranking mode are profit-oriented and neglect the interests of consumers

Search engine should provide information to consumers veritably and quickly. As one of search engines takes the bid ranking mode, Baidu makes the advertising links preferentially flack, reducing the overall efficiency of user searching. Iprospect, a well-known search engine marketing company, has revealed that: in the United States, more than $80 \%$ of Internet users do not view the search results page after the third page. More importantly, people tend to trust the companies ranked preceding more because these companies look more strength and vitality in business. (Hou Lijuan,2006,56) However, when consumers are searching on web pages, the links as of advertising resources will break the integration of resources, which will make a search order reflect much more commercialization. The advertising information transmitted to the users this way will dilute and sacrifice some consumers' interests.

Third, intervened manually, the search pages' pattern made up by the ranking links would impact corporate reputation.

In Sanlu milk powder incident, at the beginning, there were not the report that many infants and young children got sick to death for drinking Sanlu milk powder broadly, which is proved to be interrelated with the shielding of the search website. Although Baidu company denied their shielding the negative news about Sanlu milk powder, that the links could intervene the corporate reputation manually caused a widely discussion.

The ways to impact corporate reputation could be classified as two types: One is that when a company has negative news, search engine could protect this company by deleting the negative news in time according to the contract or transfering the negative news into the second page or farther of search results so as to reduce the probability of exposure. Another way is that to put the positive news on top at all time to protect the company who already paid for that. In such a profitable model, on the one hand the enterprises advertised their product and service, on the other hand, they controlled the main information to avoid issuing the negative reports and to show their advantaged reputation. Thus, bid ranking mode became an artificial channel providing information for publicity, and search engines can be profitable by manipulating corporate reputation as a media.

\section{The regulation basis of advertising Law on search engine}

China's Advertising Law mainly regulates on commercial advertising. Commercial advertising refers to those advertising for profits, which show to public for selling products or services. Whether Baidu's bid ranking service is belong to advertising service or not will depend on the provision of article 2 of China's Advertising Law.

\subsection{To Analyze the Application Basis of Advertising Law through the Relationship of Search Engine and Business}

From the perspective of civil subject, as a qualified legal person, Baidu Company may advertise. Objectively speaking, since the existing law does not regulate the advertising behavior of search engine, so let's make a judgment at first: whether the displayed links containing the keywords sold by Baidu is just the merchandise or services that the enterprises purchased to promote? We could make a deduction according to existing information: first, bid ranking mode could bring commercial interests to search engines, and we can not expect Baidu, a commercial subject and market player, to give up its profits. Second,used by the public directly, search engines provide information to the people what the public require, it is a information media people concerned. Third, on this platform, enterprise can strive for more opportunities to be approchated. Thus, we may get a conclusion: through the behavior of purchasing those keywords, bidders obtained a preferable position, which means purchasing more opportunities to advertise their products and services. For example, when you search "Bluebird" in Baidu, in three pages of the first four pages only four links are foreign to the training institutes named "BeiDa Bluebird". Based on strong market share, Baidu has led the promotion of business links to meet the purpose of the enterprises promotion, through the pre-generated contract 
getting the reward according to clicking rate. Clearly, the arrangement and propagandizing behavior of Baidu is just the services the bidders need, the rights and obligations between them is equivalent, and the services provided in the contract aims at the social benefits of advertising.

So, the authors hold that Baidu manipulating the information sources publicize the links is a behavior of advertising. Notably, the links in the right side of Baidu search pages has already been recognized as advertising. Therefore, the search engines promoting advertisements should be regulated by Advertising Law. However, as for the advertisements loccated in the left side of Baidu search page, they should be categorized into stealth advertising for its possibility of being searched, which is averse to those advertisements marked obviously. For example, the sponsor's logos and the products what the enterprises supplied appeared in the film scene, those sponsors' information in the Spring Festival evening party and so on. The keywords in website we search always have characteristics of real-time and relate to each other. But at present, China's Advertising Law does not regulate stealth advertising, so we also suggest when Advertising Law is revised, stealth advertising shall be added in the new law, and the identical criteria also should be taken.

\subsection{To Analysize the regulation basis of Advertising Law through theImpact of the BidRanking on Third-party}

From analyzation mentioned above, it can be followed that Baidu's promoting the rank for those companies that entered into contract with Baidu is an advertising behavior. Bid ranking is related to the results of enterprise sales, while the sales results necessarily involve the interests of the third-party. It is by clicking rate that the search engine companies determine the advertising fee; it is according to the money from more to less the bidders spent on advertising that the search engine rank the links. Seemingly, Baidu only changes the position of these links, but actually, this position could influence publicity directly and greatly. Without bid ranking mode, the search engines is generally dependent on the natural ranking in ordinary searching, namely the links ranking is based on equal information status among the searched words and phrases and on the consumer's click-through rate. But after bid ranking, a problem of priority among the information comes into being, no longer considering people' need at first. Priority is an effective means to antagonize an equal position. Information with a priority may have a priority in people's consciousness. Baidu, as a controller of the information sources, initiates this consciousness revolution to impact those operators including not only the customers but also those companies, which is just the reason that the company chose Baidu to promote them.

Enterprises have to advertise for their publicity, while Baidu, a search engine, should have served the searchers. However, Baidu potentially transfer the equitable selection right about information of consumers by taking the duty of promulgating advertisements to reap profits because its interests is linked closely with those enterprises. Therefore, Baidu should be regulated by Advertising Law and should bear the corresponding legal liability for his helping behavior of taking advantage of links to issue stealth advertising under Advertising Law.

\section{The Obligation and Liability under Advertising law}

According to current Advertising Law, search engines should follow the following advertising criterion when issuing the advertisements.

\subsection{Advertisement should not belittle other producers and operators' goods and service, and the authenticity and legitimacy of the index of links should be guaranteed}

According to article 12 of Advertising Law, the advertisement can't belittle other producers and operators' goods and service. In the advertising service through the keywords, links in search engines' pages should show objective information, so does the titles, which should be in conformity with the regulations about reality and legality under Advertising Law. In the case of Baidu company Vs. Jinde Company for violating its reputation, the plaintiff accused that when the users put the keywords about "Jinde", there were lots of information which contained "Jinde Swindler" on top of the pages, which constitutes disrepute.(Li Jinghua,2008)This kind of case is rather common. the principle of the regulation about market transactions According to Anti-Unfair Competition Law of the People's Republic of China, the principle of market transaction is to prohibit mendacious propaganda, whoes characteristics is by using of the mass media to create public opinion for goods or services in order to misleading people to make false declaration of intention. According to Article 21 of Advertising Law, advertisers, advertising operators and advertisement publishers should not assume any unfair competition. The authors hold that Baidu should assume the obligation of noticing whether there are baleful bidders by purchasing the keywords to top other operators' advertisement or not, and should avoid infringe interests of other merchants and consumers. Otherwise, Baidu company should take joint liability with the baleful bidders.

Advertising Law stipulates that the advertisement must be true. The service provided by Baidu and other search engines which are operated by bid ranking mode just belong to advertising service. According to law, advertisement publishers should bear the responsibility to assure the reality of the linked object. According to a investigation about "Do you have been cheated by false websites just because using Baidu search engine" in Sina portals. The number revealed that: 1 . "yes" accounting for 72 percent, 19,864 votes; 2. "no" accounting for 20 percent, 5404 votes; 3. "Do not know" 
accounting for 8 percent, 2301 votes.(Li Yanhong,2008)Being faced with such data, Baidu CEO Robin Li said that the law does not require search engine to be responsible for the release of information. .(Qin Chuan and Jin Lin,2008) As to this, we disagree. The statistics show that user's scale of using search engine has already risen to 170 million by July of 2008 in China. (Qin Chuan and Jin Lin,2008) With so many internet people, the market order, social order even economic development and society progress will not go on wheels if the authenticity of network information can't be ensured. It is undoubtedly important to confirm legitimacy of the advertising service of the search engine so as to guarantee the authenticity of website's chaining.

According to Advertising Law, the legitimacy of both the pages whose interfaces load advertisements and the pages of chaining which contain advertisements provided by search engines should be ensured. The legality of advertising contains both the content and form of advertisement and correlative behavior. The legitimacy of advertising content and form refers to the legitimacy of the title and content of the link, while both the content and the form should not damage the country and social public interests, and the advertisements should not conceal illegal purpose by legal chaining. For example, in cases of trademark infringement involving Baidu, Google, and other search engines were all caused by searching keywords. When consumers search keywords related to the information the links lead them to the false website, these search engines should take tortuous responsibility. These tortious act of Baidu and Google origined from not having done the formal examination previously. We thought that the legality of advertising action should follow the regulations of China's Anti-Unfair Competition Law and Consumer Protection Act. For example, in the link situation, mandatory link resembles to the compulsory enforcement of goods tie-ins and should be prohibited. After the contract is completed, even if the companies or individuals no longer pay the advertising fee, Baidu, as a search engine, still should ensure that the search on its website of the corporate site link is true and unobstructed by normal ranking, which is concerning the performance of post-contract obligations, subjected to regulation of Contract Law.

\subsection{The Identifiability of the Advertisement and Consumers' Right to Know}

According to Article 13 of Advertising Law, advertising should be identifiable and should enable consumers to identify it as advertising. Meanwhile, according to Article 8 of China's Consumer Protection Law, the consumers have the right to know the truth. CNNIC statistics in 2008 shows that In the world of Internet, 25.3 million people are China's Internet users, at least $60 \%$ users use search engine, and they are definitely consumers. In accordance with Consumer Protection Law, the right to know is the basic right of consumers. Internet users can not be infringed the right to know. Search engine users search keywords depending upon the trust, but the links are retrieved along with a series of advertisements; Baidu makes full use of the trust interests of consumers, but consumers have to continue to consume such a search service with flaws because advertising links page can not be retrieved with identification and with inefficient searching result. It followed from the reports of Baidu promoting the false hospital information and fake medicine reported by the CCTV program that Baidu holds an irresponsible attitude for consumers, which not only undermined the trust interests of the majority of consumers, but also, as an information releaser, induced the consumption groups.

We do believe two points need to be put forward: one is how to distinguish advertisement, another is the authenticity of the information is not easy to identify. The key to solve the two problems is to ensure the advertisement in that pages can be identified and the equity of the search results.

According to Advertising Law, Baidu's specific advertisement should be identifiable rather than cohabitating with a large number of text links, the latter is prone to make consumers misrecognize. In contrast, as to Google search engine, although the essence of the "Sponsored Links" is the same as bid ranking, the differences between biding companies' search links (on the middle of the page) and non-biding companies' search links (on the left of the page) make the Internet users understand them at ease. In practice, bid ranking mode was completely abandoned by the search industry as early as 2002 in United States. (LiuJun,2008) As the mouthpiece of the Internet, search engines are not regulated clearly by current law and they donnot guarantee the authenticity of the information, so in this situation its social consequences, especially in special industries such as medical, pharmaceutical, agricultural supplies and other industries will be unimaginable. Baidu should take more corporate social responsibility when fitering information, not only reviewing the legality and the authenticity of the information, but also ensuring the identifiability of the advertisements when ordering the links. In order to ensure the fairness of the search results, Baidu and other search engines can consider controlling the ratio of advertisements in the search page and developing new supporting technical methods to solve the social problems as soon as possible.

According to Article 13 of Advertising Law, published advertisements through the mass media should have advertising tags to distinguish from other non-advertising information so that consumers may not be misled. Therefore, Baidu should, accord to keywords' information, employs the laying out of page, or special logo, colors, text, etc. to inform consumers that which links are artificialy intervened by biding ranking and which links are screened out by computer in accordance with the rules of natural links. At the same time, the number of search links by human intervention should be restricted. All those measures will help to build a fair and equitable search order and to enhance the efficiency of the vast number consumers. 


\subsection{Improve the Reviewing Obligations of Search Engine}

With the nature of public law, Advertising Law belongs to economic law reflecting social management functions to the advertisement of our country. Therefore, when negotiating with enterprises to enter into a contract, Baidu should not only obey laws to carry out the necessary review but also should submit for approval to complete special approval process in the special industry.

First, the search engine should review the qualification of the biding business. According to Article 24 of Advertising Law, advertisers on its own or entrust to design, product, issue advertisements should provide real, legitimate and effective documentary evidence. Documentary evidences contain business license, certificate of the operation, and so on. The search engine should review advertisers in advance and bear the responsibility to provide the real legitimate merchandise and service for consumers. The operators who provided false or incomplete documents could not design, product, act as an agent, and the promulgator are not allowed to publish the advertisement. Otherwise, the search engine should bear the negative responsibility. According to Article 38, of Advertising Law, advertising operators, the publisher who knew or should know the advertisements are false but still design, product, and issue should bear the joint liability. Advertising operators and advertising publishers can not provide real name, address of advertisers should take full civil liability. Baidu promoted the false medical information of medicine business whose name and address were false, and consumers basing on the trust interests believed the false advertising and purchased their goods or services which caused damage, therefore, Baidu should take the joint liability with the advertisers. If Baidu had not reviewed enterprises' qualification and could not put forword the name and address of the advertisers, when dispute occurs, Baidu have to take the full civil liability.

Secondly, search engine should review the qualification of enterprise in special industry. Baidu's CEO Robin Li confessed that pharmaceutical industry's advertising is an important source of income for Baidu. The pharmaceutical industry, one of seven categories of providing special commodity stipulated in China's Advertising Law, have a direct impact on people's physical health, so there should have much more rigorous restrictions and reviewing standards for them. The other six special goods include medical devices, pesticides, tobacco, alcohol, food and cosmetics. Owing to the seriousness of the hazards of these particular goods, following the basic previewing, the advertisements concerning these special goods need obtaining the health authorities' health permission in accordance with China's Advertising Law. At the same time, under Article 34 of Advertising Law, the relevant administrative departments should review the content of advertising before the advertisements are published in accordance with the relevant laws and administrative regulations; without censoring, these advertisements must not be published. The authors hold that the relevant administrative departments also need to make some special obligatory term for the education review, the training departments without qualification could not be issued license.

\section{Conclusion}

In complicated cerbyspace, critical reviewing in advance reflects companies' social responsibility for consumer. However, due to the specificity of the internet, the function of searching information ranks top one in search engines' functions, with advertising issuing less important than information searching. Therefore, the search engines should not only mark ranking links by the bid logo but also do a more rigorous review to the bid ranking information, and should actively carry out the regulations of Advertising Law for specific industries by taking the supervisory obligation of substantive examination and reviewing advertisers' qualifications strictly. Otherwise, when the event of infringing consumers' right cases occurs, search engines should bear joint liability with advertisers.

\section{References}

Chuan Qin and Lin Jin. (2008). CNNIC: search engine's bid ranking mode should be regulated by legislation. [Online]Avaliable:http://news.xinhuanet.com/newmedia/2008-10/07/content_10160589.htm.(April,2009).

Jinghua Li. (2008). Jinde company implead Baidu for the right of reputation. [Online]Avaliable: Xinhua net(November $3)$.

Jun Liu. (2008).Impartiality is the fundament of achieving the accuracy---search industry in China should take immediate action to address the search for justice.[Online]Avaliable: http://www.googlechinablog.com/2008/11/blog-post_17.html(April,2009).

Lijuan Hou. (2006).Bid ranking--let consumers find you initiative.China Economy and Trade, 4,56.

Xiaolong Ma. (2003).Fiercer dispute over the search engine.China's Media Technology,5,38.
Yanhong
Li. (2008).
bid
ranking
will
go
on.New
Beijing

Newspaper .[Online]Avaliable:http://www.021admin.com/html/bocai/200812/19-2385.html(March). 